\title{
AQUECIMENTO GLOBAL: UMA PROPOSTA DE METODOLOGIA DE ENSINO DE CIÊNCIAS APLICADA EM UM COLÉGIO DO MUNICÍPIO DE NITERÓI, ESTADO DO RIO DE JANEIRO
}

\author{
Daniele P. F. de Araújo ${ }^{1}$, Maria B. P. dos Santos ${ }^{2}$ \\ ${ }^{1}$ Aluna da Pós-Graduação de Ensino em Ciências/ Universidade Federal Fluminense, \\ danielearaujobio@yahoo.com.br \\ ${ }^{2}$ Professor- Orientador-Universidade Federal Fluminens/Departamento de Físico-Química, \\ berna@vm.uff.br
}

\section{RESUMO}

O presente trabalho consiste na aplicação de uma proposta de metodologia de ensino de um tema transversal e interdisciplinar, O Aquecimento Global, em uma escola privada, denominada Equipe 1, situada no bairro do Fonseca, Niterói, estado do Rio de Janeiro. Os instrumentos utilizados foram questionários (objetivos e subjetivos), construção de vídeos, recortes de jornais, debates, exposição, dinâmicas. Os resultados obtidos demonstraram que os docentes reconhecem a importância de trabalhar a Educação Ambiental na prática educativa. Entretanto, a dificuldade de desenvolver um trabalho pautado nos princípios de transversalidade e interdisciplinaridade se faz presente devido à falta de preparação dos profissionais para desenvolver esta temática. Já os alunos afirmaram que todas as disciplinas devem tratar o assunto, desenvolvendo atividades que ajudem a interpretar a realidade que os cerca. As respostas obtidas no questionário final dos alunos foram muito satisfatórias mostrando que foram atingidos os objetivos do trabalho.

Palavras-chaves: Educação Ambiental, Aquecimento Global, interdisciplinaridade.

\begin{abstract}
The present work consists of the application of a proposal of methodology of education of crosscutting and interdisciplinary themes, Global Warming. in a private school, named Equipe 1, is located in the district of Fonseca, Niterói, Rio de Janeiro. The instruments used were questionnaires (objective and subjective), constructing videos, newspaper clippings, debates, exposition, and dynamics. The results showed that teachers recognize the importance of working the environmental education in school. However, the difficulty of developing a work outlined in the principles of crosscutting and interdisciplinary nature is present due to lack of preparedness of professionals to develop this theme. The students said that all subjects should address the issue, developing activities to help interpret the reality around them. The answers gotten in the end questionnaire of the pupils had been very satisfactory showing that the objectives of the work had been reached.
\end{abstract}

Keywords: Environmental Education, Global Warming, Interdisciplinary. 


\section{INTRODUÇÃO}

A Revolução Industrial marca, de forma muito clara o início de um processo de transformações progressivas que vêm ocorrendo em diversas áreas da humanidade, sobretudo na economia, na sociedade, na tecnologia e no meio ambiente.

Nos últimos anos, tem crescido o interesse pelas questões socioambientais visto que o caráter problemático que se insere na relação entre a sociedade e o meio ambiente vem despertando preocupações e crescente interesse social, uma vez que se torna pano de fundo para a compreensão das complexas relações que estabelecem a vida no planeta (BUCK e MARIN, 2005, p.199). As grandes questões ambientais são, dentre outros, os impactos ambientais gerados pela utilização crescente dos combustíveis fósseis, pela contaminação e poluição dos sistemas aqüíferos, pelas enchentes nas grandes metrópoles, ocasionadas em grande parte pela falta de gerenciamento dos resíduos sólidos, e às mudanças climáticas decorrentes do aquecimento global, que vem provocando um aumento na magnitude dos desastres naturais em todo o mundo.

O início da percepção pública sobre o papel da indústria e seus produtos sobre o meio ambiente surgiu com a publicação do livro "Primavera Silenciosa" de autoria da cientista Rachel Carson. Seguiram-se vários movimentos como a constituição do Clube de Roma, em 1968, e a Conferência das Nações Unidas sobre o Meio Ambiente Humano( 1972), em Estocolmo, cuja principal recomendação foi a de que deveria ser dada ênfase à educação ambiental como forma de se criticar e combater os problemas ambientais existentes na época (DIAS 2000, p. 79). Em 1982, foi constituída a Comissão Bruntland com o objetivo de avaliar os resultados da Conferência de Estocolmo, 10 anos depois. Assim, foi produzido, em 1987, o relatório "Nosso Futuro Comum" trazendo o conceito de Desenvolvimento Sustentável.

Em 1975, a UNESCO promove em Belgrado a Conferência, Work on Environmental Education, que produziu o documento, a carta de Belgrado, que formula princípios e orientações para um programa Internacional de Educação Ambiental. Adicionalmente, em outra conferência realizada, em 1977, pela UNESCO, -Conferencia Intergovernamental sobre Educação Ambiental - em Tibilisi, Geórgia, ex-URSS, se considerou que a educação ambiental deveria resultar de uma reorientação e articulação de diversas disciplinas e experiências educativas que facilitem a visão integrada do meio ambiente. (DIAS, 1991, pp. 5-6) 
No Brasil, em 1988, foi promulgada a atual constituição brasileira apresentando, no artigo 225, a incumbência do poder público de promover a Educação Ambiental em todos os níveis de ensino e a conscientização pública para a preservação do meio ambiente. Tornando-se esta uma das primeiras ações em relação à implantação da Educação Ambiental nas escolas brasileiras (DIAS, 2000).

Em 1997, o Ministério da Educação e Cultura definiu os Parâmetros Curriculares Nacional (PCNs). O MEC propõe a idéia de temas transversais, que é mais uma tentativa de articulação ente as diferentes atividades escolares e a sociedade. O conjunto de temas transversais inclui ética, pluralidade cultural, meio ambiente, saúde e orientação sexual.

Dessa forma, como preocupação com o Aquecimento Global torna-se cada vem mais evidente nos tempos atuais e diversas reuniões com líderes de vários países vêm acontecendo para discussão de soluções para interromper um aumento acelerado das concentrações dos gases do efeito estufa na atmosfera, este trabalho teve como objetivo principal trazer para o ambiente escolar a discussão sobre o Aquecimento Global.

O aquecimento global é o aumento da temperatura média da Terra causado pelo aumento, devido a ações antrópicas, dos gases do efeito estufa. O efeito estufa é um fenômeno natural que tem como finalidade impedir o esfriamento da Terra, ele ocorre quando uma parte da radiação solar refletida pela superfície terrestre é absorvida por determinados gases presentes na atmosfera e o calor fica retido não sendo libertado para o espaço. Uma série de estudos tem indicado o agravamento desse processo.

Desse modo, trabalhar esse tema na escola foi sem dúvida uma oportunidade de realizar atividades interdisciplinares, não apenas trabalhando os conceitos biológicos, mas também os fenômenos físicos e químicos envolvidos, a parte histórica, geológica, a construção de textos, enfim, muitas são as possibilidades e estratégias que podem levar os alunos a uma melhor compreensão do Aquecimento Global e suas conseqüências nos dias atuais. Além disso, pode-se contribuir para a superação de muitas visões distorcidas e reducionistas presentes nos alunos, propondo um redimensionamento do homem frente aos problemas ambientais.

\section{METODOLOGIA}


A trajetória metodológica utilizada no presente estudo foi descritiva com abordagem qualitativa e quantitativa.

O trabalho foi desenvolvido no Colégio Equipe 1, escola privada, localizada no Estado do Rio de Janeiro, na cidade de Niterói, bairro do Fonseca. O corpo docente da instituição é constituído de 39 profissionais com formação acadêmica nas diversas áreas. A escolha do local teve como parâmetro a facilidade de acesso às turmas que garantiram a realização de todas as etapas previstas neste trabalho. Optou-se por trabalhar com o Ensino Fundamental II, com turmas de responsabilidade da autora deste trabalho, com o intuito de conhecer melhor o trabalho dos professores e propor novas metodologias para os alunos. As turmas escolhidas para a realização do trabalho foram as do $6^{\circ}$ ano, constituída de quinze alunos, e do $7^{\circ}$ ano, constituída de sete alunos.

A aplicação das atividades teve como objetivo não interferir no calendário escolar, pois são atividades curtas, com tempo controlado e possibilitam uma aprendizagem significativa.

Para a implantação de uma metodologia de ensino, tomando como base o tema aquecimento global, consideraram-se as seguintes fases para estudo:

- Avaliação dos profissionais com relação à sua formação e os recursos e metodologias que utilizam para dinamizar suas aulas.

A avaliação dos professores foi realizada por meio de um questionário que continha sete perguntas objetivas e subjetivas. As questões foram separadas em grupos de interesses, de forma que as duas primeiras tratassem da formação, a terceira e a quarta de métodos de ensino e a quinta e a sexta a respeito do Aquecimento Global. Do universo de 39 professores forma escolhidos, por afinidade com o tema dentro das áreas de conhecimento, 6 professores do turno da manhã, período em que funcionava o Ensino Fundamental II.

- Uma sondagem dos conhecimentos prévios dos alunos sobre os temas Meio Ambiente, Educação Ambiental e Aquecimento Global

A sondagem foi feita por meio de aplicação de questionário e verbalização.

- Implementação das etapas da metodologia de ensino.

A metodologia aplicada teve como objetivos diagnosticar erros conceituais a respeito dos fenômenos efeito estufa e aquecimento global, inserir os conceitos 
científicos, criar métodos para facilitar a compreensão do fenômeno aquecimento global, tornando a aprendizagem fácil e divertida. O trabalho com os alunos, foi realizado cinco etapas, que estão descritas abaixo.

Na primeira etapa foi realizada uma prévia do que é aquecimento global usandose o texto do livro didático, adotado na turma, intitulado "O gás carbônico e o aumento do efeito estufa". Depois foi feita a oficina Muro das Lamentações. Essa etapa teve como objetivo esclarecer o que é o fenômeno do Aquecimento Global e discutir algumas de suas consequiências, através da realização da oficina.

$\mathrm{Na}$ segunda etapa ocorreu um debate onde uma metade da turma deveria argumentar que o aquecimento global é um fenômeno natural e a outra metade defender que é antropogênico. O objetivo dessa etapa era fazer com que o aluno entendesse que esse fenômeno é natural e agravado pelo homem, ou seja, um complementa o outro.

$\mathrm{Na}$ terceira etapa os alunos deveriam construir uma apresentação do tema, Aquecimento Global, em forma de jornal, teatro, canções, maquetes ou outra forma lúdica, para o $6^{\circ}$ ano, e em forma de vídeo para o $7^{\circ}$ ano. Essa parte do trabalho teve como objetivo a diversão e a facilitação da linguagem.

Na quarta etapa foi lido o texto, Carta da Terra, com intuído de sensibilizar os alunos para os agravantes climáticos e algumas soluções, que podem e devem ser tomadas por cada um de nós, logo após foi realizada a oficina Árvore da Esperança, local onde os alunos colocam todas suas boas intenções para um planeta melhor, em forma de desenho e palavras. Ainda nessa etapa, foi exibido o filme feito pelos alunos, que além de mostrar o potencial de criação de cada aluno, fixa o conhecimento debatido, além de incentivar o uso de novos recursos.

$\mathrm{Na}$ quinta etapa foram expostos todos os trabalhos produzidos para que estivesse ao alcance de toda comunidade escolar e pais, também foi realizado um questionário final onde se avaliou a aprendizagem dos alunos a respeito do tema.

\section{RESULTADOS}

\section{ANÁLISE DOS QUESTIONÁRIOS DOS PROFESSORES}

O primeiro grupo de questionários a ser analisado é o dos professores. Nesse grupo houve uma amostra de seis questionários preenchidos correspondentes ao 
professor de cada disciplina, isto é, Ciências, Geografia, Química, Redação, Física e Português.

Ao decorrer da avaliação do questionário ficou claro que $50 \%$ dos professores alegam não terem sido preparados pela unidade acadêmica para trabalhar com os temas transversais do PCNs. Todos os profissionais informaram que buscam meios para se atualizarem, os mais votados foram revistas, internet, e palestras, ficando em menor destaque leitura de texto científico e livros, cursos e pós-graduação. Quanto ao método para dinamizar as aulas os campeões são filmes e músicas.

Quando a pergunta foi interdisciplinaridade em aula, 83\% dos professores colocaram que se esforçam para superar a fragmentação do conhecimento, tornando suas aulas mais próximas da realidade do aluno e dos problemas da vida moderna.

No tópico, chave da pesquisa, que continha opções de visão a respeito do Aquecimento Global, $50 \%$ dos professores informaram que o aquecimento global é um fenômeno natural, porém 33\% dos professores pensam que é um fenômenos causado pelo homem e agravado pelo aumento, na atmosfera, de gases estufas, uma minoria, $17 \%$, optou pela questão que diz ser apenas o homem o causador do aquecimento global. Não houve escolha para a opção natural decorrente do efeito estufa.

Analisando as áreas de licenciatura com as respectivas respostas pode-se dizer que professores das áreas de ciências naturais e ciências da terra foram os que optaram pela resposta: "Natural agravado pelo aumento da concentração de gases estufas". Já os professores que são da área de humanas optaram pela questão que diz ser o homem o causador do fenômeno.

Da amostra de seis professores apenas o professor de português disse não ter trabalhado o tema Aquecimento Global. Os métodos utilizados pelos professores entrevistados foram o próprio livro didático, seguido de jornais e leituras, o uso de revistas, filmes e aula-show.

Para finalizar, dentre as opções contida na questão, os professores deveriam dizer o que pensam da abordagem dos meios de comunicação de massa. Obteve-se as seguintes respostas: uma parcela de $83 \%$ dos professores disse que as informações nem sempre são seguras, apenas uma pequena parcela de 17\% afirmou que as informações são incorretas, sendo precipitada a divulgação. A opção "correta" não foi apontada por nenhum dos entrevistados. 


\section{ANÁLISE DOS QUESTIONÁRIOS DOS ALUNOS}

A primeira questão do questionário dos alunos dizia respeito a confiança nos meios de comunicação de massa. Da amostra de vinte e dois alunos, 91\% afirmaram não confiar plenamente e $9 \%$ confiam nas informações transmitidas pelos meios de comunicação de massa. É muito importante perceber que tanto professores quanto alunos têm a visão que os meios de comunicação de massa, por vez, transmitem informações erradas ou distorcidas, cabendo a cada um de nós consultarmos e procurarmos apurar a veracidade da informação.

Averigou-se, também, se esses alunos já tinham trabalhado com questões ambientais, apurou-se que $86 \%$ já tinham estudado ou feito algum trabalho relacionado ao tema, e apenas $14 \%$ afirmaram não ter realizado nenhuma atividade com o tema Meio Ambiente. De alguma forma, grande parte dos alunos participantes, já trabalharam com conceitos e/ou as problemáticas envolvendo o Meio Ambiente, o que certamente forma estruturas e concepções a respeito da temática.

Pesquisou-se a visão do fenômeno do Aquecimento Global, dando duas opções: causado pelo homem ou natural. A resposta obtida foi uma unanimidade, $100 \%$, afirmando ser antropogênico, ou seja, causado pelo homem. Foi solicitado que eles citassem três conseqüências do Aquecimento Global. Das respostas obtidas percebe-se que poluição (19\%), aumento do nível do mar (17\%) e aumento de temperatura (17\%) são os mais apontados.

Foi a intenção saber quais materiais os alunos gostam que sejam usados em sala de aula pelos professores para dinamizar as aulas. A grande maioria ainda prefere os vídeos $(27 \%)$ e as experimentações $(24 \%)$. Depois de uma breve conversa com os alunos, a conclusão alcançada foi que essas duas formas de construção de conhecimento, são as que eles têm menos acesso fora do espaço escolar.

Para finalizar o questionário foi importante saber quais disciplinas os alunos pensam que deveria abordar a Educação Ambiental. Das respostas obtidas 35\% acham que é a disciplina de Ciências, e 22\% que é a disciplina de Geografia.

Na realidade essas são as disciplinas que ainda tem um enfoque naturalista por isso ainda são as mais apontadas para abordar temas relacionados a Educação Ambiental, o que não tira a responsabilidade das demais disciplinas de abordá-la. Portanto, a melhor opção é a que confere $10 \%$, ou seja, todas, pois nela haverá uma abordagem com uma visão interdisciplinar. 


\section{MURO DAS LAMENTAÇÕES}

Após a leitura do texto "O gás carbônico e o aumento do efeito estufa" e um breve comentário a respeito do aquecimento global, foi realizada a oficina muro das lamentações.

A oficina foi o momento onde cada aluno teve que previamente procurar, por meio de pesquisa, uma reportagem ligada a catástrofes e fenômenos naturais que ocorreram nos últimos meses e que tenham relação com ao aquecimento global.

Em círculos cada aluno se levantou e explicou porque lamentava aquele acontecimento, depois de sua fala, foi aberto para que todos os demais alunos comentassem a reportagem do colega expositor. Após esse momento a reportagem era afixadas no muro das lamentações.

Essa atividade foi feita pelas duas turmas, $6^{\circ}$ e $7^{\circ}$ ano, e ficou exposta no mural da escola.

Durante o desenvolvimento dessa atividade foi interessante notar as descobertas feita por eles, a cada relação feita dos acontecimentos ao fenômeno do aquecimento global.

\section{DEBATE: NATURAL X ANTROPOGÊNICO}

Nessa etapa, por meio de sorteio, dividiu-se cada turma em dois grupos. Cada grupo debateu a respeito dos seguintes temas: Aquecimento global causado pelo homem e aquecimento global um fenômeno natural. As equipes tiveram uma semana para preparar o material para o debate.

Nessa atividade as duas equipes ficaram frente a frente, e cada uma teve um tempo de 4 minutos para a defesa da idéia que foi proposta e 2 minutos para se opor aos argumentos da outra equipe.

Essa atividade ocorreu tanto no $6^{\circ}$ ano quanto no $7^{\circ}$ ano, e nela foi possível notar a dificuldade que os alunos tiveram para defender que o aquecimento global é um fenômeno natural agravado pelo homem. Alguns disseram ser impossível contra argumentar o grupo que defendia que o aquecimento global era causado pelo homem. Até então essa dificuldade já era previsível.

\section{APRESENTAÇÃO DOS TRABALHOS CONFECCIONADOS}


Nessa atividade os alunos foram estimulados a produzirem trabalhos em grupo, os alunos do $6^{\circ}$ ano foram divididos em grupos, cada grupo escolheu a estratégia, dentre as oferecidas (criação de jornal, teatro, música etc.), para trabalhar o efeito estufa, as causas, consequências e soluções para o aquecimento global.

Após a turma ter sido dividida em quatro pequenos grupos, contendo quatro alunos, foi sorteado o tema que cada grupo deveria dar enfoque no seu trabalho, as estratégias ficaram a escolha do grupo.

Os trabalhos foram apresentados duas semanas após a organização dos grupos, essa atividade foi executada junto ao planejamento do ano letivo, como uma das avaliações, sendo esta pontuada de zero a dez. A nota de cada aluno foi usada para a formação da média trimestral

Os alunos do $7^{\circ}$ ano confeccionaram trabalhos com uso de programas do office, como o power point, paint e movie maker, eles deveriam criar um vídeo que abordasse os temas.

A intenção de cada grupo de realizar o trabalho com temas diferentes era de juntar esses vídeos formando um só, para então ser exibido para as duas turmas.

Além de usar recursos de informática, que faz sucesso entre os alunos, promover a criação de vídeos foi alvo de excitação, pelo recurso, pelo tema e pela espera da apresentação. Nesse momento ocorreu maior interação por parte dos alunos para cumprir a tarefa.

\section{ÁRVORE DA ESPERANÇA}

Foi solicitado aos alunos do $7^{\circ}$ ano que escrevessem no papel estratégias para proteger o planeta do aquecimento global e os colocassem na árvore da esperança e explicitassem seus pontos de vista a respeito .

Aos alunos do $6^{\circ}$ ano foi solicitado que fizessem um desenho de situações que favorecem a diminuição do aquecimento global no planeta.

Todos os desenhos foram colocados ao lado da árvore da esperança no mural principal.

\section{AVALIAÇÃO FINAL E EXPOSIÇÃO}


A avaliação final dos trabalhos realizados pelos 21 alunos foi feita de forma sucinta, por meio de questionário onde os alunos responderam cinco perguntas relacionadas ao tema trabalhado.

Na primeira questão foi solicitado que os alunos escrevessem o que entendiam a respeito do efeito estufa, visto que ao decorrer das falas durante a confecção dos trabalhos, mostravam uma leve mistura a respeito dos dois fenômenos: o efeito estufa e o buraco na camada de ozônio. Dentre as respostas obtidas para essa pergunta foram encontradas duas opções: fenômeno que permite que o planeta se torne habitável e, fenômeno que retém parte dos raios solares que atravessa a atmosfera terrestre. As respostas citadas pelos alunos estão de acordo com o desenvolvimento dos trabalhos em sala, visto que o efeito estufa é um fenômeno que permite a vida em nosso planeta através da retenção de raios ultravioleta que chegam a Terra.

Na segunda questão eles deveriam responder sim ou não. Ao responder essa pergunta pode-se avaliar o nível de compreensão dos alunos perante o trabalho realizado, visto que o efeito estufa é o ponto de partida para se entender o aquecimento global. As respostas obtidas foram de $100 \%$ dos alunos afirmando não ser um problema o efeito estufa.

$\mathrm{Na}$ terceira questão eles deveriam dizer o que é Aquecimento Global. Nessa questão foram obtidas quatro tipos de resposta que se completam e estão de acordo com o que foi discutido nas aulas. Nesse tópico da avaliação escrita, 74\% dos alunos, apontaram o aquecimento global como um fenômeno que aumenta a temperatura da Terra, e 16\% dos alunos afirmaram que o aquecimento global acorre pelo acúmulo de gases estufa.

$\mathrm{Na}$ questão quatro, de modo resumido, os alunos deveriam apontar duas alternativas para solucionar o aquecimento global. A solução mais apontada foi o uso de energia renovável (42\%), e a justificativa de que o uso de combustíveis fósseis tem contribuído, significativamente, para o fenômeno do aquecimento global o que ocorreu, também, com a segunda opção mais eleita pelos alunos (24\%). Assim, de acordo com as respostas dos alunos, o uso de energia renovável e a diminuição no uso de carros proporcionarão uma menor liberação de gases GEE provenientes de combustíveis fósseis. A terceira opção mais apontada pelos alunos foi o reflorestamento (20\%), e a explicação de que o reflorestamento é uma forma de diminuir a concentração na atmosfera de um dos gases que mais contribui para o aquecimento do planeta. . Em menor destaque apareceu a opção, controlar a poluição do ar (14\%), que é bastante 
abrangente, estando ligada a queimadas, fumaça das indústrias, fumaça dos carros etc. Uma opção não citada pelos alunos foi a diminuição das queimadas que contribui com o processo inverso ao desmatamento. Todas as opções descritas pelos alunos foram alvo discursão em sala de aula, o que proporcionou respostas mais direcionadas nesse questionário.

Na ultima questão eles deveriam apontar que substância antrópica tem agravado, ou seja, contribuído para o aumento do aquecimento global. As respostas obtidas foram o aumento de emissão do gás carbônico $(81 \%)$. O segundo mais citado foi a fumaça com $9 \%$ e o metano e vapor d água foram apontados em $5 \%$ das respostas.

\section{CONCLUSÃO}

O projeto foi desenvolvido por meio de uma metodologia participativa e coletiva, abordando o aquecimento global do ponto de vista natural, econômico, científico e social, possibilitando a construção do conhecimento de modo integrado. $\mathrm{Na}$ visão das pesquisadoras não basta apenas atividades didáticas bem planejadas, é necessário também que elas permitam a expressão oral ou escrita dos alunos, possibilitando troca de conhecimento.

Com a execução de todas as etapas do projeto foi possível concluir que as atividades de oficinas, montagem de vídeos e debates, no ensino de ciências, são sem sombra de dúvida, um recurso bastante motivador, estimulando a curiosidade e a postura crítica dos alunos. Tais práticas pedagógicas colaboraram para discussão dos fenômenos observados e puderam desenvolver a capacidade dos alunos, na compreensão dos conceitos tratados em aula, vistos na televisão e lidos nos jornais, muitos, às vezes abstratos.

Os resultados obtidos na avaliação final indicam que houve construção significativa do conhecimento durante o desenvolvimento do projeto, pois grandes partes dos alunos apresentaram respostas mais elaboradas para questões ligadas ao Aquecimento Global.

\section{REFERÊNCIAS}

ARAÚJO. D.R.V. 2005. Repensando Práticas em Educação Ambiental: experiência e saberes de professoras das series inicias do ensino fundamental no Município de Teixeira de Freitas, Bahia. Niterói. UFF mestrado em Educação, centro de estudos sociais aplicados. 
BARBIERI, J.C. 2005. Desenvolvimento e meio ambiente: as estratégias de mudança da Agenda 21. $7^{\circ}$ ed. Petrópolis, RJ. Editora Vozes. p.53.

BUCK , S.; MARIN, A. A.Educação para pensar socioambientais e de qualidade de vida.Educar, Curitiba, n 25, 197-212, 2005, Editora, UFPR

CÉSAR, J., SEZAR, S. \& BEDAQUE, P. Ciências: Entendendo a Natureza. $6^{\circ}$ ano. 2005, $21^{\circ}$ edição. São Paulo. Ed. Saraiva. p.130.

DIAS, Genebaldo Freire. Os Quinze Anos da Educação Ambiental no Brasil: um depoimento. Em Aberto, MEC, Brasília, v. 10, no 49, jan./mar. 1991.

DIAS, Genebaldo Freire. Educação Ambiental: princípios e práticas. São Paulo: Gaia, 2000.

FREIRE, Paulo. Educação como Pratica de liberdade. Ed. Paz e Terra, 23 Edição. Rio de Janeiro, 1999.

OLIVEIRA, E.M. de . 2000. Educação ambiental uma possível abordagem. Ed. IBAMA. $2^{\circ}$. Brasília. p. 150. 